\title{
Chauvigny de la Bretonnière, La Religieuse en chemise et Le Cochon mitré
}

\section{Chiara Mainardi}

\section{(2) OpenEdition \\ Journals}

\section{Edizione digitale}

URL: http://journals.openedition.org/studifrancesi/5609

DOI: 10.4000/studifrancesi.5609

ISSN: 2421-5856

\section{Editore}

Rosenberg \& Sellier

\section{Edizione cartacea}

Data di pubblicazione: 1 septembre 2011

Paginazione: 404

ISSN: 0039-2944

\section{Notizia bibliografica digitale}

Chiara Mainardi, «Chauvigny de la Bretonnière, La Religieuse en chemise et Le Cochon mitré», Studi Francesi [Online], 164 (LV | II) | 2011, online dal 30 novembre 2015, consultato il 13 janvier 2021. URL: http://journals.openedition.org/studifrancesi/5609 ; DOI: https://doi.org/10.4000/studifrancesi.5609

Questo documento è stato generato automaticamente il 13 janvier 2021.

\section{(2) $\odot \Theta \Theta$}

Studi Francesi è distribuita con Licenza Creative Commons Attribuzione - Non commerciale - Non opere derivate 4.0 Internazionale. 


\title{
Chauvigny de la Bretonnière, $L a$ Religieuse en chemise et Le Cochon mitré
}

\author{
Chiara Mainardi
}

\section{NOTIZIA}

CHAUVIGNY DE LA BRETONNIÈRE, La Religieuse en chemise et Le Cochon mitré, édités par Jean SGARD, Publications de l'Université de Saint-Étienne, Saint-Étienne, 2009, 204 pp.

1 Edito da Jean Sgard, professore emerito dell'università di Grenoble III, questo volume accoglie, insieme ad un'importante introduzione, l'edizione moderna di due opere attribuite a François Chauvigny de la Bretonnière, Vénus dans le cloître ou la Religieuse en chemise e Le Cochon mitré. Giornalista, romanziere e libertino, Chauvigny ebbe una breve carriera letteraria della durata di soli cinque anni. Prima di ciò, il silenzio del chiostro benedettino, dopo, quello della prigione.

2 Vénus dans le cloître (1683), dialogo filosofico e pedagogico ardito e apertamente trasgressivo, è un mélange originale di libertinaggio e politica, dove traspare la denuncia dell'ambiente clericale.

3 Due anni più tardi, Chauvigny spinge la sua audacia più lontano: abbozza contro l'arcivescovo Le Tellier e Mme de Maintenon un violento pamphlet, Le Cochon mitré (1685). Grazie al suo lavoro di giornalista aveva avuto modo di trarre dalla cronaca del tempo il materiale necessario alla stesura di quest'opera che si inscrive all'interno della polemica antiassolutistica di Luigi XIV. A causa dei contenuti del pamphlet, Chauvigny viene rapito, portato alla Bastille, torturato e poi rinchiuso a vita nella prigione di Mont Saint-Michel.

4 Ma le due opere hanno successo anche senza il suo intervento, attraverso interessanti vicende editoriali: viene persa traccia del manoscritto della bozza del Cochon mitré, ma esso rinasce in un altro, omonimo, che riprende l'originale di Chauvigny. Per quanto 
riguarda Vénus dans le cloitre, l'editore Jacques Durand decide insieme ad altri collaboratori di ripubblicare l'opera di Chauvigny arricchendone i tre entretiens con altri tre apocrifi.

5 Per l'edizione moderna dei tre primi entretiens di Vénus dans le cloître, il curatore si è affidato all'edizione del 1683, per il quarto entretien ha seguito quella del 1685 e per gli ultimi due il testo del 1719, intervenendo a correggere gli errori, modernizzando l'ortografia e normalizzando la punteggiatura. Per il Cochon mitré il curatore riporta l'edizione del 1689 che custodisce le tracce del pamphlet di Chauvigny, ne modernizza l'ortografia, ma ne rispetta la punteggiatura.

6 Chauvigny, coniugando libertinaggio e politica, esprimendo la sua rivolta, ha tentato di opporsi all'oppressione dei potenti, dei violenti e della Chiesa. 